\title{
CHANGES IN LEAF AND SHOOT WATER STATUTES OF GRAPEVINES IN RESPONSE TO CONTRASTING WATER AVAILABILITY AND GLYCINE BETAINE PULVERIZATION
}

\author{
Omar Tourhan Jalil JALIL ${ }^{1 \oplus}$ \\ Ali SABIR ${ }^{2, *}$ ( \\ ${ }^{1}$ Selcuk University Graduate School of Natural and Applied Science, Konya \\ ${ }^{2}$ Selcuk University Agriculture Faculty Horticulture Department, Konya \\ "Corresponding Author:asabir@selcuk.edu.tr
}

\begin{abstract}
Drought is one of the most widespread stress factors adversely affecting plant growth, crop yield and quality. In Subtropical region, on the face of global warming, temperature extremes aggravate the negative effects of drought. Increased resistance to stress has been achieved in several plants by exogenous application of various organic osmoprotectants. In this study, the role of glycine betaine (GB) as exogenous application, is aimed to investigate for increasing grapevine stress tolerance to drought. The grapevines of Alphonse Lavallée' cultivar, grafted on the rootstock $41 \mathrm{~B}$, were subjected to four different applications; (1) full irrigation (FI) as control (irrigation at field capacity level), (2) deficit irrigation (DI, 50\% of FI), (3) DI plus 5000 ppm GB pulverization, and (4) DI plus 10000 ppm GB pulverization in a pot experiment under glasshouse condition. Leaf fresh weight of vines subjected to DI was $31.8 \%$ lower than those of FI vines. GB appeared to exert an influence on leaf water statute, slightly alleviating the leaf water loss resulting from water shortage. GB treatments, regardless of the concentration, slightly increased the fresh weight of the leaves $(22.2 \%$ lower than FI). Investigations on leaf turgid weight and dry weight were also similar to those of fresh weight in that the highest and the lowest values were determined in FI and DI applications, respectively. Reduction in shoot water content in response to water deficit was closely related to the decrease in leaf water content.
\end{abstract}

Keywords: Drought, Grapevine, Organic Osmoprotectants, Glycine Betaine

Received: 30.10.2017 Accepted: 20.11.2017 Published: 20.12.2017

\section{INTRODUCTION}

Environmental stress factors such as drought, temperature extremes, salinity, nutrient imbalances adversely affect plant growth, crop yield and quality. Less than $10 \%$ of the world's arable lands is estimated to be free of such major environmental stresses [1]. Drought and salinity stresses are the most widespread stress factors $[2$, 3]. Around $45 \%$ of the world agricultural lands are subject to continuous or frequent drought [4]. Low precipitation, high surface evaporation, using saline water in irrigation and improper cultural practices are among the major contributors to the decreasing yield.

Temperature extremes aggravate the negative effects of other stresses, including drought and salinity, on agricultural production and quality of commodities. Fischer and Byerlee [5], for instance, indicated that heat stress adversely affects grain yield and quality in $40 \%$ of the irrigated wheat growing area of the world. On the other hand, global warming is an increasing environmental issue with its differential effects on plants according to the regions. It is envisaged that developing countries will be affected to a greater extent, thereby resulting in increased food insecurity therein [6].

Plant tolerance to abiotic stresses is a complex physiology due to the complexity of interactions between stress factors and various molecular, biochemical and physiological phenomena affecting plant growth. Development of plants tolerant to environmental stresses is proven as a promising approach, which may aid to satisfy growing food demands of the world. Such challenge necessitates knowledge of the genetic controls and physiological mechanisms of the contributing traits at certain developmental stages of plant. Stress factors may provoke osmotic stress and protein denaturation in plants, leading to cellular adaptive responses such as accumulation of compatible solutes and induction of stress proteins [7]. 
Over synthesis of organic solutes to protect plants from stress, is one of the most common stress responses in plants [8]. These solutes, referred to osmoprotectants, protect cellular components from dehydration injury. These protectants include proline, polyols, sucrose, trehalose and quaternary ammonium compounds such as glycine betaine, alaninebetaine, prolinebetaine, choline $O$-sulfate, hydroxyprolinebetaine, and pipecolatebetaine [9].

Increased resistance to abiotic stresses has been achieved in several plants by exogenous application of various organic osmoprotectants. In spite of this fact, however, this approach in viticulture has not received sufficient consideration in the literature [10]. For this reason, in this study, the role of glycine betaine as exogenous application, is aimed to investigate for increasing grapevine stress tolerance, in particular in response to drought.

\section{MATERIALS AND METHODS}

\section{Study Design}

The study was performed in the controlled glasshouse of Selcuk University, Konya, Turkey. The vines of 'Alphonse Lavallée' table grapevine cultivar was grown on the rootstock $41 \mathrm{~B}$ in pots containing equal mixture of peat and perlite. The experiment consisted of four different applications; (1) full irrigation (FI) as control (irrigation at field capacity level), (2) deficit irrigation (DI, 50\% of FI), (3) DI plus $5000 \mathrm{ppm}$ glycine betaine (GB) treatment, and (4) DI plus 10000 ppm glycine betaine (GB) treatment. The experimental vines were spur pruned to leave 4 or 5 cane with a total of 8 or 10 buds per vine. The shoots were tied with thread to wires $2.3 \mathrm{~m}$ above the pots to let plants grow on a perpendicular position to ensure similar cultural practices [11]. The vines received the same annual amount of fertilizer (approx. $30 \mathrm{~g} \mathrm{~N}, 18 \mathrm{~g} \mathrm{P}, 30 \mathrm{~kg} \mathrm{~K}$, and micro elements per vine) from April to August.

\section{Experimental Condition}

To determine the required volume of irrigation water, similar pots filled with growth medium were placed in large plastic buckets and irrigated with a known volume of water, and then kept for seven hours to attain field capacity. Afterwards, the drained water was measured and subtracted from the total volume of water applied. The value obtained (mean of three pots) was considered as optimum to keep the soil moisture at field capacity. Each pot-grown vine was given 0.8-1.5 L every day [12]. This amount was considered as the volume of the irrigation water that has to be used to attain $100 \%$ field capacity (FI). Fifty percentage amount of FI was considered as DI [13]. Irrigations were regulated according to soil water matric potential $(\Psi \mathrm{m})$ levels using tensiometers (The Irrometer Company, Riverside, CA) placed at a depth of $20 \mathrm{~cm}$ (about rooting depth) and approximately $12 \mathrm{~cm}$ from the trunk and were applied from bud break (early March) to the end of vegetation period (beginning of October). Soil tensiometers (irrometer) were employed for a more realistic expression of soil water depletion in terms of $\Psi \mathrm{m}$ following the slightly modified procedure described by Myburgh and van der Walt [14]. Changes in $\Psi \mathrm{m}$ were continuously monitored with daily readings at around $13: 00 \mathrm{pm}$ as well as before and after irrigations [15]. To ensure the uniformity, the water was applied via drip systems. Repeated readings during several days showed that the tensiometers readings at midday $(13.00 \mathrm{pm})$ were constantly around $0.8-14$ $\mathrm{cb}$ and $30-38 \mathrm{cb}$ for FI and DI conditions, respectively. For DI, irrigation was started around 32-34 cb and was terminated when the calculated amount of water was applied. The start value of irrigation system for FI group vines were adjusted to around $10 \pm 2 \mathrm{cb}$ to ensure that the full water amount of field capacity is provided. Relatively higher air temperature in the glasshouse was also performed to simulate the typical semi-arid Mediterranean climate. During vegetation periods (March-October) for two experimental years, daily air temperature and relative humidity, recorded using data logger (Ebro EBI 20 TH1) inside the glasshouse, were $22-40^{\circ} \mathrm{C}$ and $28-65 \%$, respectively. During the hot and dry summers for both years (from the beginning of June to September), excessive heat accumulation in glasshouse was avoided by opening the roof and sidewall windows as well as slight whitewash painting (providing approx. 15-20\% natural light reflection) to keep clusters and young leaves from burning.

\section{Leaf Mass and Leaf Relative Water Content (LRWC)}

LRWC were investigated on fully expanded leaves of experimental grapevines of each treatment [16]. Fifteen sun-exposed transpiring leaves per treatment were sampled early in the morning and immediately weighed to obtain fresh weight. To investigate the relative water content (RWC) of the mature leaves, the freshly sampled leaves were rehydrated by submerging in 
deionized water for $24 \mathrm{~h}$ in dark to obtain turgid weight [17]. Measurements were performed after gently wiping the water from the leaf surface with soft tissue paper. At the end of rehydration period, leaf samples were weighed to obtain final turgid mass (TM) and then placed in an oven at $70^{\circ} \mathrm{C}$ for $48 \mathrm{~h}$ in order to found the dry mass (DM). All the mass measurements were made using an analytical scale, with precision of $0.001 \mathrm{~g}$. Values of FM, $\mathrm{TM}$, and DM were used to calculate RWC, using the equation suggested for leaf by Weatherley [18]:

$$
\operatorname{LRWC}(\%)=[(\mathrm{FM}-\mathrm{DM}) /(\mathrm{TM}-\mathrm{DM})] * 100
$$

\section{Summer Shoot Features}

Summer shoot features such as shoot relative water content (SRWC), shoot and pith diameters were investigated in the late summer period when the shoot growth was approaching to cessation. Shoot features was determined using a total of fifteen samples per a plot consisted of shoot pieces from upper, middle and lower parts by cutting ca. $50 \mathrm{~mm}$ shoot lengths with a bud in its center. Mean value of upper, middle and lower shoot parts was calculated. Fresh and dry masses of each pieces were attained using the same procedure followed in the leaves. SRWC was calculated as the percentage water loss using the following equation suggested for leaf by Myburgh and van der Walt [14];

$$
\operatorname{SRWC}(\%)=[(\mathrm{FM}-\mathrm{DM}) /(\mathrm{TM}-\mathrm{DM})] * 100 .
$$

\section{Statistical Analysis}

Data were subjected to the variance analyses using SPSS 13.0 for Windows (SPSS Inc., Chicago, IL, USA) at $\mathrm{P}<0.05$ level. The mean values of three of each treatment were compared using the least significant difference (LSD) test.

\section{RESULTS AND DISCUSSION}

In order to investigate the effects of irrigation applications at different levels and leaf glycine betaine (GB) treatments, leaf and summer shoot characteristics such as fresh weight, turgid weight, dry weight and relative water content were determined.

\section{Changes in Leaf Mass and Leaf Relative} Water Content (LRWC)

The highest leaf fresh weight was obtained from FI application while, on the other hand, the lowest value was recorded from DI. Leaf fresh weight of vines subjected to DI was $31.8 \%$ lower than those of FI vines. GB treatments, regardless of the concentration, slightly increased the fresh weight of the leaves $(22.2 \%$ lower than FI). Investigations on leaf turgid weight and dry weight were also similar to those of fresh weight in that the highest and the lowest values were determined in FI and DI applications, respectively. As known, vine water status depends on many factors such as soil texture, percentage of stones, rooting depth, rainfall, evapotranspiration, and leaf area $(16,19)$. In the present study water deficit impaired the leaf weight and relative water content features of 'Alphonse Lavallée' grapevine. GB treatment had no remarkable alleviating effect on leaf water statute.

Table 1. Differences in leaf characteristics in response to water applications and glycine betaine treatments.

\begin{tabular}{lccc}
\hline Treatments & Leaf fresh weight $(\mathrm{g})$ & Leaf turgid weight $(\mathrm{g})$ & Leaf dry weight $(\mathrm{g})$ \\
\hline FI & $2.79 \pm 0.04 \mathrm{a}$ & $3.35 \pm 0.06 \mathrm{a}$ & $0.67 \pm 0.04 \mathrm{a}$ \\
DI & $1.90 \pm 0.05 \mathrm{c}$ & $2.60 \pm 0.07 \mathrm{c}$ & $0.58 \pm 0.03 \mathrm{~b}$ \\
DI+5000 ppm GB & $2.17 \pm 0.03 \mathrm{~b}$ & $2.97 \pm 0.07 \mathrm{~b}$ & $0.60 \pm 0.03 \mathrm{~b}$ \\
DI+10000 ppm GB & $2.17 \pm 0.02 \mathrm{~b}$ & $3.01 \pm 0.08 \mathrm{~b}$ & $0.61 \pm 0.01 \mathrm{~b}$ \\
\hline LSD (\%5) & 0.59 & 0.10 & 0.04
\end{tabular}

FI: Full irrigation, DI: Deficit irrigation. Mean values indicated by different letters identify significantly different groups $(P<0.05)$. $(\mathrm{n}=15)$. 


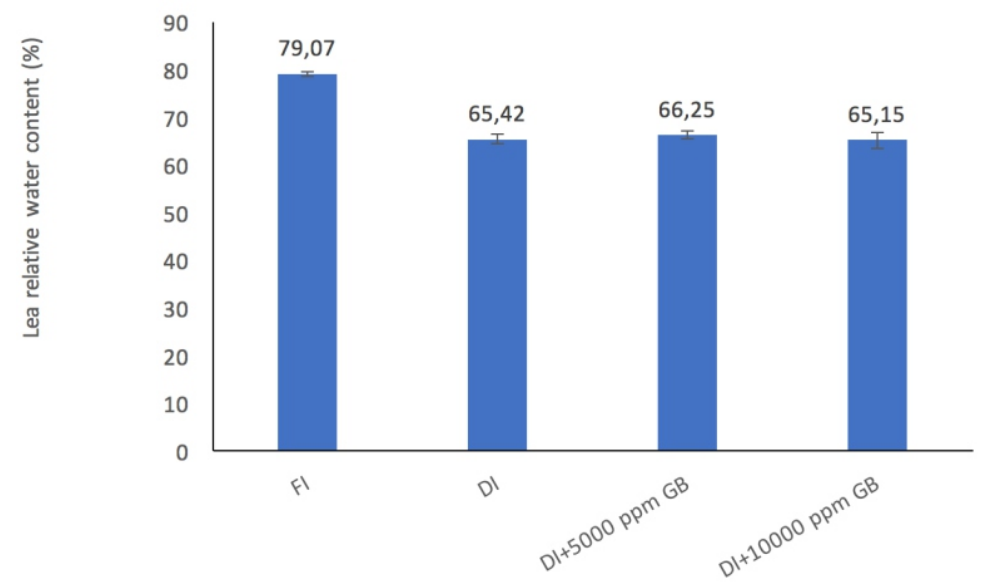

Figure 1. Differences in leaf relative water content (LRWC, \%) as affected by irrigation level (FI: full irrigation, DI: deficit irrigation) and GB treatments (5000 and $10000 \mathrm{ppm})$. Values of bars indicated by different letters identify significantly different groups $(P<0.05$, LSD).

Considering the findings on the leaf features of the present study, it is evident that the water statute of mature leaves is a sensitive indicator for grapevine response to water deficit as stated by Sabir [20]. However, a lower relative water content of the leaf does not necessarily indicate that the physiological capacity of the vine is low. As stated by Dry and Loveys [21] the capacity of a vine may be closely related to the total grape yield rather than to the activity rate such as total vegetative growth. Also, grapevines, like many other plants, have developed long- and short-term acclimation strategies to cope with water stress, such as modifying the leaf anatomy [19]. Studying on the effect of different levels of salinity on seedless grape cultivars 'Askari' and 'Yaghuti', Alirezanezhad et al. [22] found that leaf LRWC decreased with increasing salinity in both cultivars, in different magnitudes depending on acclimation strategy aptitude of the studied cultivars.

LRWC response of grapevines to various treatments has been depicted in Fig 1. Analysis of variance showed that LRWC of the grapevines received FI application was significantly higher than all the other treatments. GB treatments in both concentrations had no significant effect on RLWC, because they were in the same statistical group with DI application. Ability to maintain a high LRWC at a low water availability may display greater strength of the cell wall and its capability to withstand against the water loss [23].

Changes in Summer Shoot Quality Features Relative Water ontent (CRWC)

Certain shoot parameters regarding to cane quality have been shown in Table 2 . Summer shoot diameter and pith diameter presented slight nonsignificant variation among the treatments.

Table 2. Differences in summer shoot hardiness features in response to water applications and glycine betaine treatments.

\begin{tabular}{lccc}
\hline Treatments & Shoot diameter $(\mathrm{mm})$ & Pith diameter $(\mathrm{mm})$ & Shoot/pith diameter \\
\hline FI & 4.15 & 2.09 & $1.98 \pm 0.05 \mathrm{c}$ \\
DI & 4.13 & 2.00 & $2.07 \pm 0.25 \mathrm{~b}$ \\
DI+5000 ppm GB & 4.13 & 1.91 & $2.16 \pm 0.06 \mathrm{a}$ \\
DI+10000 ppm GB & 4.21 & 2.13 & $1.98 \pm 0.17 \mathrm{c}$ \\
\hline LSD (\%5) & $\mathrm{ns}$ & $\mathrm{ns}$ & 0.07 \\
\hline $\begin{array}{l}\text { FI: Full irrigation, DI: Deficit irrigation, ns: nonsignificant. Mean values indicated by different letters identify } \\
\text { significantly different groups }(P<0.05) .(\mathrm{n}=15) .\end{array}$
\end{tabular}




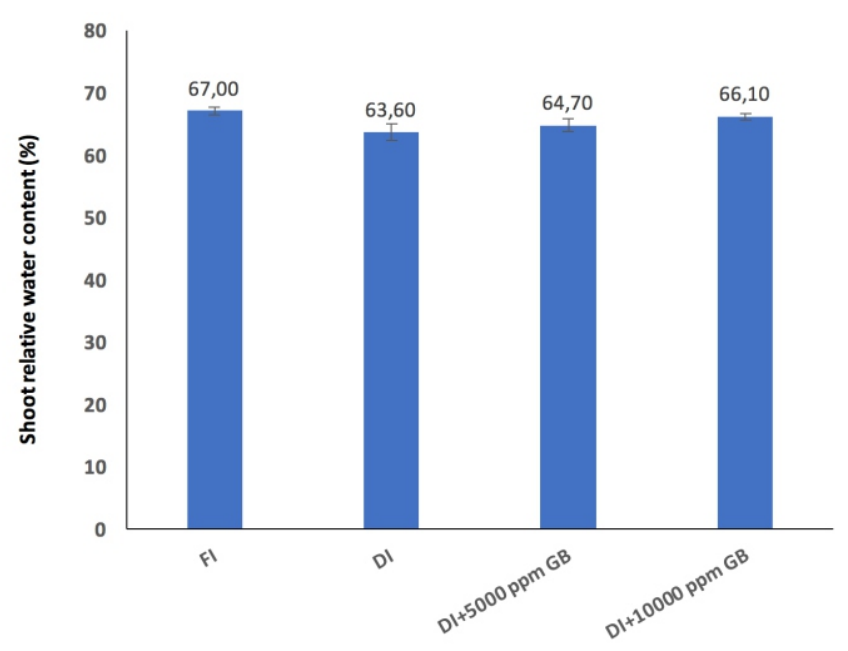

Figure 2. Differences in summer shoot relative water content (LRWC, \%) as affected by irrigation level (FI: full irrigation, DI: deficit irrigation) and GB treatments (5000 and $10000 \mathrm{ppm}$ ). Values of bars indicated by different letters identify significantly different groups $(P<0.05$, LSD $)$.

Nonetheless treating the grapevines with DI plus 10000 ppm GB resulted in the highest shoot and pith diameters. $\mathrm{Bu}$ the magnitude of the treatments were not as high as those observed for leaf investigations. On the other hand, shoot/pith value, as a better measurement for evaluating shoot hardiness, significantly varied according to the treatments. The highest shoot/pith value was obtained from DI plus 5000 ppm GB treatment (2.16) while the lowest value was recorded from FI and DI plus $10000 \mathrm{ppm} \mathrm{GB}$ (with the same value of 1.98). Lower pith diameter and higher shoot/pith value means higher xylem and phloem tissue ring formation in response to $5000 \mathrm{ppm}$ GB. It is well known that quality of a shoot is positively correlated with the ratio of shoot width/pith [24, 25]. Studies revealed that pith diameter diminishes with the higher carbohydrate accumulation in xylem and phloem, and consequently freezing tolerance of the cane and bud cells increase [26, 27].

DI slightly but significantly reduced the SRWC determined as the mean value of basal, middle, and upper pieces with a node lengthwise of the summer shoots of each plant (Figure 2). Considering the mean values the highest SRWC was determined in FI vines $(67.0 \%)$ while the lowest value $(63.6 \%)$ was found in DI. SRWC of vines in response to $10000 \mathrm{ppm}$ concentration $(66.1 \%)$ was higher than those ofDI.

Correlation between SRWC and LRWC was illustrated in Fig 3. The pooled data on the water content parameters revealed that there was significant positive correlation between leaf and cane water statutes. Reduction in SRWC in response to water deficit was closely associated with decrease in LRWC.

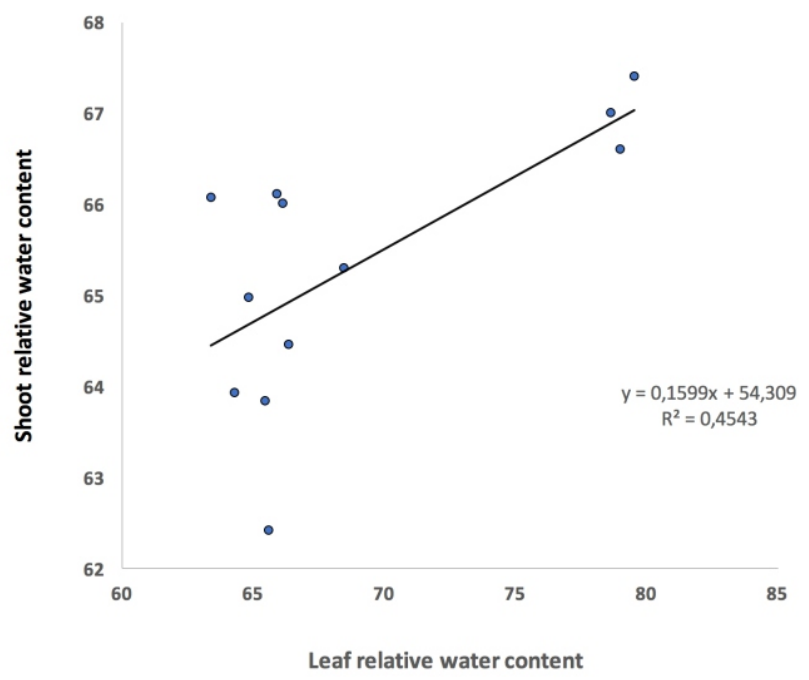

Figure 3. Correlation between summer shoot relative water content and leaf relative water content 


\section{CONCLUSION}

Climate change, resulting higher temperatures and more frequent water deficits in agricultural areas, is a major challenge for viticulture in the coming decades. If the climate change tendency proceeds, grape quality and yield will be negatively affected in the near future. Hence, growers need to implement adaptive strategies to ensure production of economically high-quality grapes at acceptable yields in a dryer climate. Among various options, the use of adapted plant materials and plant protectants are better tools, because of their advantages of being environmentally friendly and cost effective. Certain solutes, referred to osmoprotectants, protect cellular components from dehydration injury. Glycine betaine, in the present study, appeared to exert an influence on leaf water statute, slightly alleviating the leaf water loss resulting from water shortage. Glycine betaine treatments, regardless of the concentration, increased the fresh and dry weights of the leaves of grapevines subjected to deficit irrigation. Therefore, glycine betaine pulverization might be one of environmentally friendly cultural strategy to alleviate negative effects of drought in viticulture.

\section{ACKNOWLEDGEMENT}

This article has been generated from Master Science Thesis of Omar Turhan Jalil Jalil. The authors wish to thank Scientific Research Project Coordination Unit (BAP) for supporting the study (Project no: 17201121).

\section{REFERENCES}

[1] Dudal, R. (1976). Inventory of major soils of the world with special reference to mineral stress. Cornell University Agriculture Experiment Station, Ithaca, 3 pp.

[2] Ashraf, M. (1994) Breeding for salinity tolerance in plants. Critical Review in Plant Science, 13, 17-42.

[3] Kalender, M.A., Topak, R. (2017) Irrigation performance of Ilgin irrigation association. Selcuk Journal of Agriculture and Food Science, 31, 59-67.

[4] Bot, A.J., Nachtergaele, F.O., Young, A., (2000) Land resource potential and constraints at regional and country levels. World Soil Resources Reports 2000 No: 90114 pp.

[5] Fischer, R.A., Byerlee, D.R. (1991) Trends of wheat production in the warmer areas: major issues and economic considerations. In: Saunders, D.A. (Ed.), Wheat for Nontraditional, Warm Areas. CIMMYT, Mexico, DF, pp. 3-27.

[6] Rosenzweig, C., Parry, M.L. (1994) Potential impact of climate change on world food supply. Nature, 367, 133-138.

[7] Zhu, J.K. (2002) Salt and drought stress signal transduction in plants. Annu. Rev. Plant Physiol. Plant Molecular Biology, 53, 247-273.

[8] Serraj, R., Sinclair, T.R. (2002) Osmolyte accumulation: can it really help increase crop yield under drought conditions? Plant Cell Environment 25, 333-341.

[9] Rhodes, D., Hanson, A.D. (1993) Quaternary ammonium and tertiary sulfonium compounds in higher-plants. Annu. Rev. Plant Physiol. Plant Molecular Biology, 44, 357-384.

[10] Ashraf M., Foolad M.R. (2007) Roles of glycine betaine and proline in improving plant abiotic stress resistance. Environmental and Experimental Botany, 59, 206-216

[11] Sabir, A. (2013) Improvement of grafting efficiency in hard grafting grape Berlandieri hybrid rootstocks by plant growth-promoting rhizobacteria (PGPR). Sci. Hortic., 164, 24-29.

[12] Satisha, J., Prakash, G.S., Venugopalan, R. (2006) Statistical modeling of the effect of physiobiochemical parameters on water use efficiency of grape varieties, rootstocks and their stionic combinations under moisture stress conditions. Turkish Journal of Agriculture and Forestry, 30, 261-271.

[13] Sabir, A., Kara, Z. (2010) Silica gel application to control water runoff from rootzone microenvironment's climate of grapevine rootstocks grown under drought condition. International Sustainable Water and Wastewater Management Symposium 2, 1365-1372, 26-28 Oct. Konya, Turkey.

[14] Myburgh, P. A. and van der Walt, L. D. (2005) Cane water content and yield responses of Vitis vinifera L. cv. Sultanina to overhead irrigation during the dormant period. South African Journal of Enology and Viticulture, 26, 1-5.

[15] Okamoto, G., Kuwamura, T., Hirano, K. (2004) Effects of water deficit stress on leaf and berry ABA and berry ripening in Chardonnay grapevines. Vitis, 43, 15-17. 
[16] Tramontini, S., van Leuwen, C., Domec J. C., Irvine, A. D., Basteau, C., Vitali, M., Schulz, O. M., Lovisolo, C. (2013) Impact of soil texture and water availability on the hydraulic control of plant and grape-berry development. Plant and Soil, 368, 215-230.

[17] Yamasaki, S., Dillenburg, L.R. (1999) Measurements of leaf relative water content in Araucaria angustifolia. Revista Brasil. de Fisiol. Veget., 11, 69-75.

[18] Weatherley, P.E. (1950) Studies in the water relations of the cotton plant. I. The field measurement of water deficits in leaves. New Phytologist, 49, 81-87.

[19] Tsegay, D., Amsalem, D., Almeida, M., Crandles, M. (2014) Responses of grapevine rootstocks to drought stress. International Journal of Plant Physiology, 6, 1-6.

[20] Sabir, A. (2016) Physiological and morphological responses of grapevine $(V$. vinifera L. cv. 'Italia') leaf to water deficit under different rootstock effects. Acta Scientiarum Polonorum Hortorum Cultus, 15, 135-148.

[21] Dry, P. R. and Loveys, B. R. (1998) Factors Influencing Grapevine Vigor and the Potential for Control with Partial Root Zone Drying. Australian Journal of Grape and Wine Research, 4: 140-148.

[22] Alirezanezhad, A., Mohammadi, A., Mohammadi, N. (2013) Effect of different levels of salinity on two seedless grape cultivars 'Askari' and 'Yaghuti'. International Journal of Agriculture and Crop Science 5, 632-637.

[23] Irigoyen, J.J., Emerich, D.W. and SanchezDiaz, M. (1992) Water stress induced changes in concentrations of proline and total soluble sugars in nodulated alfalfa (Medicago sativa) plants. Journal of Plant Physiology, 84, 55- 60.

[24] Hunter JJ., Volschenk, CG., Le Roux DJ., Fouche GW., Adams L. (2004) Plant material quality. ARC Infruitec-Nietvoorbij, Private Bag X5026, 7599 Stellenbosch, South Africa, 18p.

[25] Dardeniz, A., K1smal1, İ. (2001) Investigations on yields of cuttings and some morphological properties of 140 Ruggeri and 1103 Paulsen American vine rootstocks grown in Çanakkale-Umurbey. Ege University, Agriculture Faculty Journal,
38, 9-16.

[26] Hamman, RA., Dami, IE., Walsh, TM., Stushnoff, C. (1996) Seasonal carbohydrate changes and cold hardiness of Chardonnay and Riesling grapevines. American Journal of Enology and Viticulture, 47, 31-36.

[27] Grant, TN., Dami, I.E., Scurlock, JT., Streeter, J. (2009) Variation in leaf and bud sugar concentration among Vitis genotypes grown under two temperature regimes. Canadian Journal of Plant Science, 89, 961968. 